\title{
The Impact of Time Delay on the Content of Discussions at a Computer- Mediated Ergonomics Conference
}

\author{
Byron C. Huntley ${ }^{*}$ and Andrew Thatcher* \\ Department of Psychology, School of Human \& Community Development, University of the Witwatersrand, Wits, 2050, \\ South Africa
}

\begin{abstract}
This study investigates the relationship between the content of computer-mediated discussions and the time delay between online postings. The study aims to broaden understanding of the dynamics of computer-mediated discussion regarding the time delay and the actual content of computer-mediated discussions (Knowledge construction, Social aspects, Number of words, and Number of postings). A sample drawn from the computer-mediated discussions of the CybErg 2005 virtual ergonomics conference served as the data for this study. The Interaction Analysis Model was utilised to analyse the level of knowledge construction in the content of the computer-mediated discussions. The correlation results demonstrate that Knowledge construction, Social aspects and Number of words generated within postings were independent of, and not affected by, the Time delay between the postings and the postings from which the replies were formulated. When greater numbers of words were utilised within postings, this was typically associated with a greater level of knowledge construction. Social aspects in the discussion were found to neither advantage nor disadvantage the overall effectiveness of the computer-mediated discussion.
\end{abstract}

Keywords: Online discussion, knowledge construction, time delay, Interaction Analysis model, content analysis, social aspects.

\section{INTRODUCTION}

The use of computer conferencing and online discussion is becoming more prevalent (Gunawardena, Lowe, and Anderson, 1997) and important as the internet has enabled many online forms of communication (Glance et al., 2005). Most disciplines, including business and education, have been subject to internet discussion groups (Matzat, 2004). Communication via online discussions is increasingly important as it allows for learning and knowledge to be constructed (Schellens $\&$ Valcke, 2004) within a distributed community of contributors. For example, Schellens and Valcke (2004) found interactions within an online discussion group to be highly taskorientated resulting in high degrees of knowledge construction. Online discussions also close the divide between people from nations all over the world (Cairncross, 1997). New forms of collaborative work, study and community are provided for by various types of online discussions that reduce both time and distance barriers (Kanuka \& Anderson, 1998). Communication about various constructs of work between people from a variety of locations was traditionally very difficult as it necessitated identifying a specific venue and arranging related travel expenses in order to get everyone to that location. With the advent of online conferencing and discussion, not only can people communicate with others from any location that has online access, but costs related to travel are significantly diminished or even non-existent (Thatcher, 2006).

\section{Face-to-Face Versus Computer-Mediated Communica- tion}

While this study specifically focuses on computermediated communication it is necessary to first discuss the

*Address correspondence to either author at the Department of Psychology, School of Human \& Community Development, University of the Witwatersrand, Wits, 2050, South Africa; E-mail: huntleybk@telkomsa.net or

Andrew.Thatcher@wits.ac.za qualities of face-to-face discussion in order to contrast these qualities with the types and quality of communication that happens online. In this section we concentrate on aspects such as spontaneity and social presence which are curtailed in many forms of online communications. Computermediated, text-based communication is often deemed to be inferior to face-to-face communication since the absence of nonverbal cues and other aspects of social presence (Daft \& Lengel, 1986; Sproull \& Kiesler, 1986; Walther, 1992) and the relatively long time delays between communication points may result in non-interactive discourse (Schoberth, Preece \& Heinzl, 2003). However, Garrison, Anderson and Archer (2000) have argued that people can adapt new ways to make their social presence felt within computer-mediated environments. Face-to face communication is typified as being less structured, spontaneous, fast-paced and transitory in comparison to text-based communication (Garrison et al., 2000). The rapidity of dialogue under these conditions facilitates the dual exchange of ideas and concepts to build and extend discourse, especially in smaller groups that are carefully moderated (Garrison et al, 2000). In addition, face-toface communication allows for multiple social, emotional, and contextual cues through a speaker's tone, facial expression and body movements (Garrison et al. 2000). It has been suggested that the asynchronous nature of many forms of computer-mediated communication combined with this lower social presence means that the interactivity of online discussions would be adversely affected (Pendergast, 2006; $\mathrm{Tu}, 2002)$. By implication then, the longer the time delay between communication messages, the greater the reduction in the ability of online text-based communication to facilitate the development of academic discourse. Newman, Johnson, Webb and Cochrane (1997), for example, found that the reduced interaction speed of computer-mediated conferencing prevented spontaneity and the generation of new ideas. It has been argued that within asynchronous online discussions, 
time frames for the discussion and for the replies between postings (participant's individual contributions to the discussion) should therefore be limited, as quicker sequences of postings result in better interaction within the discussion (Pendergast, 2006). If participants are aware that postings are being generated regularly within the online discussion, they will feel obliged to contribute to the discussion (Pendergast, 2006). Therefore, this study will research whether increases in time delay detract from the discussion and possibly terminate the discussion. This is investigated in this study by analysing where the highest time delay exists within a discussion thread and whether the greater time delays are associated with a termination in the discussion thread. In addition, this study investigates whether shorter time delays are associated with increased numbers of postings and by implication improved discourse.

\section{Qualities of Computer-Mediated Conferencing}

As computer-mediated conferencing becomes more accepted, the strengths and constraints of the diverse media that can support or impede learning and communication becomes paramount (Gay, Martin \& Pena-Shaff, 2001). According to Matzat (2004), many studies have shown that users of online discussions find that they are helpful for creating new ideas as well as providing research information. Garrison et al. (2000) indicated that due to a greater time for reflection within text-based communications, they may be more preferable to oral communication when the objective is higher-order cognitive learning. The existence of temporal and spatial independence within online discussions creates a learning environment which is unique and valuable (Rourke, Anderson, Garrison \& Archer, 2001). However, in two studies (Conner, 1992; McCarty, 1992), many users complained of low quality and low extent of actual discussion within online discussion groups. Many studies have argued that online discussions are poor mediums for solving intellectual controversies (Hiltz, 1984; Harasim \& Winkelmans, 1990; Lewenstein, 1995). Therefore, research has presented both advantages and disadvantages of computer-mediated conferencing and by analysing the content of the particular online discussion, the body of knowledge defining whether online discussions are beneficial or not may be extended.

Little research has investigated the relationship between time delay and the actual content of online discussions (e.g. Knowledge construction, Number of words, presence of Social aspects, plus Number of postings within the discussion thread). Therefore, this study can add to a body of knowledge that is broadly concerned with quantitative and qualitative measures of the actual content of discussion largely independent of aspects of time. Previous research has looked at the length of messages and has concluded that while longer messages tend to be "richer" (in part resulting from more opportunities for social presence cues), shorter messages generate more discussion postings (Schoberth et al., 2003). Similarly, in comparison to face-to-face communication, computer-mediated communication was found to be leaner and more task-oriented (Garrison et al., 2000; Matzat, 2004). This study investigates the ability of online textual communication, within an academic conference environment, to facilitate the depth of knowledge construction and critical debate. Knowledge construction refers to the learning process when individuals communicate their thoughts, opinions, ideas, dis/agreements, negotiated statements and new meanings with one another (Gunawardena et al., 1997). As individuals communicate with one another within the discussion and share ideas, opinions and negotiate new meanings as the discussion progresses, so too is the level of knowledge construction seen to increase (Gunawardena et al., 1997). Pea (1993) states that knowledge is constructed through combined efforts towards shared objectives and/or through dialogue and conflicts between different perspectives. Gunawardena et al. (1997) states that as a result of participant interaction, the discussion could potentially progress from lower to higher mental functions, essential to the process of co-creating higher knowledge and deeper/shared understanding. Levin, Kim, and Riel (1990) state that as a result of this "constructivist" understanding, participants interact to produce new knowledge and arrive at new understandings of meanings.

In contrast, social aspects, sometimes referred to as social talk, are off-the-topic discussions or parts of the discussion, such as plans or processes occurring outside of the discussion, or are personal comments (Chen, Lee, Chu, Wang \& Jiang, 2005). Social aspects, such as greetings, are important in establishing rapport and aiding the flow of dialogue. In addition, expressing feelings and emotions within online discussions often occurs via the use of emoticons (i.e. such as "smileys" (;, :), ;) ) that are used to convey emotional meaning and social nuances to text $(\mathrm{Tu}, 2000)$. Kreijns, Kirschner, and Jochems (2002) stated that social aspects within a discussion were crucial in supporting learning processes. Steinkuchler, Derry, Levin, and Kim (2000) found that social aspects contributed to the online discussion by keeping the general conversation flowing and on-task, whilst ensuring that group members were understanding one another. Contrary to this finding, Walther (1996) argues that more effective online discussions contain fewer social aspects within the discussion. Lipponen, Rahikainen, Lallimo, and Hakkarainen (2001) and Badri, Grasso, and Leng (2003) regard there to be a conflict between effective discussions and social aspects. Therefore, there seems to be some conflict between research findings on whether social aspects within an online discussion are beneficial or destructive. This research will explore whether or not social aspects impact on the flow of discussions or the construction of knowledge.

\section{The Online Conference: CybErg 2005}

The online discussions to be analysed within this study occurred within the CybErg 2005 conference. The CybErg conferences are regularly occurring (triennially in the year before the International Ergonomics Association Congresses) ergonomics and human-factors engineering online conferences (Thatcher, 2006). Previous CybErg conferences have been held in 1996, 1999, 2002, and 2005. At these conferences, various key stakeholders in this industry from all over the world posted their academic papers on the conference website. The conference website was open for discussions over a one-month period where authors and conference participants were afforded the opportunity to discuss these papers with other participants by means of online discussions facilitated through an asynchronous text-based bulletin board (Thatcher, 2006). At the most recent CybErg conference in 2005 (the fourth conference in the series) there were 127 
online discussion topic threads spanning across organisational, general, cognitive, safety and security, and physical ergonomics; building and maintaining online discussions; and general discussions (Thatcher, James \& Todd, 2005). The majority of the discussions were based around 75 academic papers, 6 invited papers, and 3 keynote address papers. While there were 160 registered participants, only 83 participants $(52 \%)$ actually contributed to the discussions (Thatcher, 2006). Qualitative ratings demonstrated that participants felt that the quality of the papers and online discussion wee typically better than those encountered at face-toface conferences (Thatcher, 2006).

\section{Research Questions}

Based on the evidence presented in this review of the literature it is therefore proposed that an increased time delay between postings would detract from the content of the discussion, and would be associated with the termination of the discussion. In addition, this study investigates whether shorter time delays have been associated with an increased numbers of postings. By analysing whether time delay affects the content of the discussion, and possibly whether higher time delays are associated with a termination in discussions, guidelines used to assist the structuring of discussions can be recommended for computer-mediated conferences. In particular, it is possible to review whether specific time parameters should be set for individuals to reply to a posting, or whether time parameters are insignificant to the content of the discussion.

In attempting to set out the research questions it is first useful to define the possible variations under investigation. The first variable under consideration is that of the Time delay. The Time delay refers to the amount of time that has passed between an initial posting and its reply. Within the context of asynchronous text-based communication the Time delay could theoretically vary from a few seconds (or virtually instantaneous) to indefinitely. The second variation in this study refers to the distinction between a posting and a discussion thread. A posting refers to a defined response by a participant that has been finalised and submitted for others to view, whereas a thread refers to a sequence of related postings on a topic. In the research questions, "at the posting level" means that each individual posting is treated as the unit of analysis whilst research questions at the "discussion thread" level mean that the discussion thread as a whole is treated as the unit of analysis. The third point refers to the attributes of the posting. There are a number of different possibilities; the Highest level of knowledge construction achieved within a discussion thread or a posting; the presence of Social aspects; or the Number of words. The fourth point refers to defining the term "First". The "First" posting refers to the initial posting that starts off a particular discussion thread. For example, the "First" time delay refers to the delay in responding to the very first posting within a discussion thread and its attributes.

In the set of research questions below, we have refrained from mentioning each particular possible combination as this would lead to a list of more than twenty individual research questions. Instead we outline the basic research questions that we are attempting to answer within this particular study.
Research question 1: What are the frequencies of the phases of Knowledge construction at an online conference?

Research question 2: At the posting level, what are the interrelationships between the Time delay, the level of Knowledge construction, the Social aspects, and the Number of words, between postings?

Research question 3: At the discussion thread level, what are the interrelationships between the Number of postings, the Highest level of knowledge construction, the Point at which the highest level of knowledge construction was achieved, and the Point at which the highest time delay existed, within the discussion threads?

Research question 4: What are the interrelationships between the posting level variables (Time delay, Knowledge construction, Social aspects, and Number of words) and the discussion thread variables (Number of postings, Highest level of knowledge construction achieved, Point at which the highest level of knowledge construction was achieved, and Point at which the highest time delay existed between postings)?

Research question 5: How does the "First" time delay, the "First" level of knowledge construction, the "First" number of words, and the "First" social aspects impact on later postings within a discussion thread?

\section{METHOD}

The discussion postings were taken from CybErg 2005, where the discussion threads and the individual postings within the discussion threads were the units of analysis. A total of 30 discussion threads constituting 262 usable postings were randomly selected, yet purposefully scrutinised, so as to ensure that they met the minimum criteria of three usable reply postings and at least two separate contributors for each discussion thread. These 262 reply postings constituted $31 \%$ of the total number of postings $(\mathrm{N}=850)$ at the online conference, where a large proportion of the total postings were initiating postings (roughly $30 \%$ of the postings were initial postings at the conference).

\section{Procedure}

Within the selected discussion threads, the individual postings have been analysed for; time delay between the initial posting and its reply posting (Time delay); the level of knowledge constructed (Knowledge); presence of social aspects (Social aspects); and the number of words (Words). The discussion threads themselves have been analysed for; the number of postings present (Npost); the highest level of knowledge construction achieved within the discussion thread (Hi know); the point in the discussion thread at which the highest time delay existed between postings (Prop hi delay); and the point of the discussion thread at which the highest level of knowledge construction was achieved (Prop hi know). Each of the variables and how they will be operationalised will now be dealt with in greater detail.

"Time delay" represented the amount of time elapsed between an initial posting made and the reply to that initial posting. As Time delay was a pivotal variable within this research project, it was measured as an interval variable so as to extract maximum information from this variable. However, due to the large variance within the time delay variable, 
time values were rounded off to the nearest half hour. In addition, the time delay distribution was found to be nonnormally distributed. The natural log of all time delay values was therefore used to normalise the data and was utilised within the statistical analysis.

The content of the discussions was analysed for the amount of "Knowledge construction" (Knowledge) present within the postings. Within each posting, the highest level of knowledge construction was adjudged by utilising the Gunawardena et al. (1997) Interaction Analysis Model (IAM). The modified version of the full Gunawardena et al. (1997) IAM is to be found in Appendix A. The Gunawardena et al. (1997) IAM codes knowledge construction into five ascending phases of knowledge construction. Phase I (lowest level of knowledge construction) represents the sharing and/or comparing of information, Phase II represents the exploration of dissonance and inconsistency amongst ideas and concepts, Phase III involves the negotiation of understanding and joint construction of new knowledge; Phase IV occurs when generated knowledge is tested and modified; and Phase V (highest level of knowledge construction) involves summarising agreements amongst participants and the application of newly constructed understanding (Gunawardena et al., 1997).

The "Words" variable represented the number of words utilised within the posting. Number of words is of a lesser focus than Time delay and the variance in amount of words utilised was expected to be lower than Time delay. The number of words might also reflect other nuances such as writing style, the first language of the participant, the choice of words, and the technicality of the subject area. Therefore, Number of words was rather operationalised by specifying groups into which the number of words present in the postings could be placed instead of as a continuous variable. After carefully considering the analysed data, the groups were specified as; group 1 (brief response) with between 0 and 50 words; group 2 (moderately short response) with between 51 and 100 words; group 3 (moderate response) with between 101 and 170 words; group 4 (moderately lengthy response) with between 171 and 250 words; and group 5 (long response) with 250 words or more.

The content of the postings was analysed for the amount of "Social aspects" in terms of; no Social aspects (category 0 ), minimal Social aspects (category 1) and large Social aspects (category 2). Thus, no Social aspects refer to a posting which constitutes completely on-the-topic discussion. Minimal Social aspects refers to a posting which includes only one or two emoticons (e.g. smiley face, frown etc.) or very little social talk and off-the-topic discussion in relation to onthe-topic discussion. Large Social aspects refer to a posting having multiple emoticons, and/or a large degree of social talk and off-the-topic discussion in relation to on-the-topic discussion.

Within each discussion thread, the Number of postings present was also recorded as a variable. The "Number of postings" (Npost) variable refers to the amount of relevant postings present within the discussion thread. This is due to the fact that all relevant postings are those which are replying to previous postings within the discussion thread and not those postings which are simply additional discussion "initiating" statements or statements that do not seem to reply to any previous postings. The "Highest level of knowledge construction" (Hi know) achieved within each discussion thread also constituted a variable. This variable was operationalised by investigating the highest levels of knowledge construction achieved within each of the postings of the particular discussion thread and selecting the posting with the highest level. This value represented the highest level of knowledge construction achieved within a particular discussion thread. Each discussion thread was also analysed for where the highest phase of knowledge construction existed. This was operationalised by determining at what proportion of each discussion thread the posting with the highest level of knowledge construction existed (Prop hi know). For example, if a discussion thread had ten postings, and the posting with the highest level of knowledge construction was posting number eight, then the proportion of the discussion thread at which the highest level of knowledge existed was $80 \%$. If the highest level of knowledge construction existed in more than one posting, the last posting with that level was utilised. Similarly, the "Proportion of the discussion thread at which the highest time delay exists between postings" (Prop hi delay) was also calculated. For example, if a discussion thread had five postings, and the fourth posting had the highest time delay from the posting to which it was replying to, relative to all other time delays within the discussion thread, then the proportion of the discussion thread at which the highest time delay existed was $80 \%$.

\section{Analysis}

The Gunawardena et al. (1997) IAM is a commonly utilised content analysis technique. Marra, Moore, and Klimczak (2004) and Kanuka and Anderson (1998) found the Gunawardena et al. (1997) IAM as a useful tool for analysis of the content of online discussions. Therefore, the highest level of knowledge constructed within each posting was assessed using the Gunawardena et al. (1997) IAM which was specifically designed to evaluate knowledge constructed at computer-mediated professional development conferences. To ensure the non-bias and reliable application of the Gunawardena et al. (1997) IAM, inter-rater reliability was tested. Inter-rater reliability levels for knowledge construction were established by having an independent rater analyse 52 of the postings $(20 \%)$. Inter-rater reliability was high with a Cohen's kappa of 0.94 .

\section{RESULTS}

First, an example from the discussion threads of the $\mathrm{Cy}$ bErg 2005 conference and how it was analysed is provided from within the discussion thread "Possibility of forming a Virtual Community from CybErg participants" is presented in Table 1. Everything typed in bold signifies the researchers' content analysis on the posting. As this posting was replying to a posting made on the 29 September at 06:51, the time delay constituted 32 hours and 9 minutes, rounded off to 32 hours. In accordance with the Gunawardena et al. (1997) IAM model, the statements which expressed the contributor's opinions and observations of virtual communities reflected a phase I level of knowledge construction, whilst those statements which proposed new statements regarding virtual community technologies resulted in knowledge being co-constructed and thus reflected a phase III level of knowledge construction. Phase III therefore represented the highest 
level of knowledge constructed within this particular posting. As the entirety of the posting consisted of on-the-topic discussion, with no social talk, off-the-topic discussion or emoticons, it was labelled 0 for social aspects. A word count of the posting revealed 95 words in total (a moderately short response).

Table 1. Example Analysis of a Discussion Posting

Posted: 30 September 2005 15:01
$\begin{aligned} & \text { 32 hours delay from } \\ & \text { previous posting }\end{aligned}$
There are interesting discussions going on at various places
around the net at the moment-driven by different activists,
bloggers, companies. (I)
It seems that successful communities are not strictly
regulated but fluid, and lately more dispersed server-wise (I).
The technology is catching up-XML-feeds (rss, atom),
trackbacks, tagging systems like del.isio.us, technorati help
create conversations between websites and people (III).
Technologies like foaf and xfn help with tracking relations of
the kind-“I know these people" (III).
When creating a community it should definitely reflect the
need for it, rather than artificially creating it (III)
[Contributor name]
Social aspects = 0 Words = 95 (group 2) Highest knowledge
construction level = III

Table 2. Example Analysis of a Discussion Posting Reflecting the Social Aspect Variable

\begin{tabular}{|c|c|}
\hline Posted: 12 October 2005 02:10 & $\begin{array}{l}10 \text { hours } 30 \text { minutes } \\
\text { delay from previous } \\
\text { posting }\end{array}$ \\
\hline \multicolumn{2}{|c|}{$\begin{array}{l}\text { Hello [name]! You have suddenly emerged and I've noted your } \\
\text { comments on a couple of earlier forums this morning! Thanks for } \\
\text { looking in... this symposium has not grabbed the audience so far! } \\
\text { I think it is so far from manual handling issues that tend to } \\
\text { dominate most ergo discussions that it sinks below the horizon of } \\
\text { possible new territory for ergo mining! [I] }\end{array}$} \\
\hline \multicolumn{2}{|c|}{ [Contributor name] } \\
\hline \multicolumn{2}{|c|}{ Social aspects $=2$ Words $=65($ group 2$)$} \\
\hline \multicolumn{2}{|c|}{ Highest knowledge construction level $=\mathbf{I}$} \\
\hline
\end{tabular}

Table 2 presents an analysed posting which contained large amounts of the Social aspect variable. This posting was found within the discussion forum on the "Safety and Security Symposium". The majority of this posting constitutes off-topic discussion due to a large amount of personal reference and comment about the discussion not strictly related to its content (safety and security issues). As a result, this posting was analysed as possessing large amounts of Social aspects (category 2).

In answering research question 1 , the highest percentages of knowledge construction were found in the following descending order in the postings analysed: Phase I 52\% $(\mathrm{N}=$ 136), Phase III 30\% ( $=79)$, Phase II 11\% ( $=29)$, Phase IV $5 \%(\mathrm{~N}=13)$, and Phase V $2 \%(\mathrm{~N}=5)$.

In terms of research question 2, 3 and 4, the results of the interrelationships at the posting and the thread level can be found in Table 3. At the posting level, Time delay was found not to be significantly related to Knowledge construction $(\mathrm{r}=$ $0.11, \mathrm{p}>0.05)$, social aspects $(\mathrm{r}=-0.07, \mathrm{p}>0.05)$, or Number of words $(r=0.03, p>0.05)$. Knowledge construction and Social aspects were also not significantly related $(\mathrm{r}=$ $0.08, p>0.05)$. Knowledge construction and the Number of words was however highly significant $(\mathrm{r}=0.53, \mathrm{p}<0.01)$ and the effect size was strong and positive. The relationship between Social aspects and Number of words was nonsignificant $(\mathrm{r}=0.01, \mathrm{p}>0.05)$. The relationship between the Number of postings and Time delay was negative and significant, but the effect size was weak $(r=-0.25, \mathrm{p}<0.01)$. Time delay was not significantly related to the Highest level of knowledge construction achieved within discussion threads $(r=-0.01, p>0.05)$, but was significantly, and negatively, related to the Proportion of the discussion thread at which the highest level of knowledge construction was achieved, even though the effect size was weak $(r=-0.13, p$ $<0.05)$. The Highest level of knowledge construction achieved within particular discussion threads was significantly related to Knowledge construction at the posting level $(\mathrm{r}=0.22, \mathrm{p}<0.01)$, but the effect size was weak. The positive relationship between the Number of postings within discussion threads and the Highest level of knowledge construction at the discussion thread level $(r=0.35, \mathrm{p}>0.05)$, although not statistically significant, had a moderate effect size and thus may have practical significance. With reference to the results presented in Table $\mathbf{3}$, no further significant relationships were found.

The mean proportion of the discussion threads at which the highest time delay existed between postings was $70.5 \%$, with a median value at $74.6 \%$ and a mode of $100 \%$. The mean proportion of the discussion threads at which the highest level of knowledge construction was found was $68.6 \%$, with a median value at $71.43 \%$, and a mode of $100 \%$.

The results of research question 5 are presented in Table 4, where "First" refers to the first reply posting within a discussion thread and its attributes (e.g. "First" knowledge is the highest level of knowledge construction achieved within the first reply posting of a particular discussion thread). The time delay of the first reply posting within discussion threads ("First" time delay) was significantly, and negatively related to the Number of postings within discussion threads $(\mathrm{r}=$ $0.44, \mathrm{p}<0.01)$. However, the "First" time delay was not significantly related to the Highest level of knowledge construction within discussion threads $(\mathrm{r}=-0.08, \mathrm{p}>0.05)$ and the Proportion of the discussion threads at which the Highest level of knowledge construction was achieved $(r=-0.20, p>$ $0.05)$. The Proportion of the discussion threads at which the highest time delay existed between postings was significantly, and negatively, related to the "First" time delay $(r=-$ $0.40, p<0.05)$ and the "First" number of words $(r=-0.37, p$ $<0.05)$, but not significantly related to the "First" knowledge $(\mathrm{r}=-0.26, \mathrm{p}>0.05)$ or the "First" social aspects $(\mathrm{r}=0.26, \mathrm{p}$ $>0.05$ ), suggesting that social aspects play only a small role in online discussions. Even though the relationship between the Highest level of knowledge construction achieved within discussion threads was not significantly related to "First" knowledge, a positive and moderate-weak effect size (0.31) was found. With reference to the results presented in Table 4, no further significant relationships were found.

In order to gain a perspective of the strengths of the meaningful relationships comparatively, the top ten effect sizes are presented in Table $\mathbf{5}$ in descending order. 
Table 3. Results for Variables at the Posting and Discussion Thread Level

\begin{tabular}{|c|c|c|c|c|c|c|c|}
\hline & Time Delay & Knowledge & Social Aspects & Words & Npost & Hi Know & Prop Hi Know \\
\hline \multicolumn{8}{|l|}{ Posting Level } \\
\hline Knowledge & 0.11 & 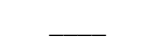 & 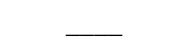 & 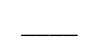 & 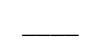 & 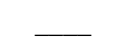 & 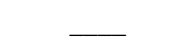 \\
\hline Social aspects & -0.07 & -0.08 & 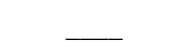 & 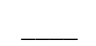 & 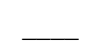 & $\longrightarrow$ & $\longrightarrow$ \\
\hline Words & 0.03 & $0.53 * *$ & 0.01 & 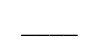 & 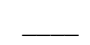 & 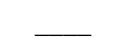 & 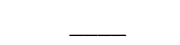 \\
\hline \multicolumn{8}{|l|}{ Thread Level } \\
\hline Npost & $-0.25 * *$ & 0. & 0.02 & 0.07 & _ & 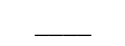 & 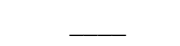 \\
\hline Hi know & -0.01 & $0.22 * *$ & -0.02 & 0.10 & 0.35 & 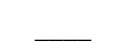 & 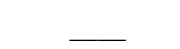 \\
\hline Prop hi know & $-0.13 *$ & 0.08 & -0.04 & -0.06 & 0.02 & -0.16 & 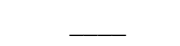 \\
\hline Prop hi delay & -0.12 & 0.01 & 0.04 & -0.10 & 0.12 & 0.07 & 0.18 \\
\hline
\end{tabular}

$*=$ Significant At $\mathrm{p}<0.05 * *=$ Significant at $\mathrm{p} \leq 0.01$.

Table 4. 'First' Posting Relationships with Discussion Thread Variables

\begin{tabular}{|c|c|c|c|c|}
\hline & Npost & Hi Know & Prop Hi Know & Prop Hi Delay \\
\hline 'First' time delay & $-0.44 *$ & -0.08 & -0.20 & $-0.40^{*}$ \\
\hline 'First' social aspects & -0.10 & 0.02 & -0.09 & 0.26 \\
\hline 'First' amount of words & 0.07 & 0.02 & -0.17 & $-0.37 *$ \\
\hline
\end{tabular}

$*=$ Significant at $\mathrm{p}<0.05^{* *}=$ Significant at $\mathrm{p} \leq 0.01$

\section{Table 5. Top Ten Effect Sizes}

\begin{tabular}{|l|c|c|}
\hline \multicolumn{1}{|c|}{ Relationship } & Effect Size & p \\
\hline \hline Knowledge with Words & 0.53 & $\mathrm{p}<0.01$ \\
\hline Npost with 'First' time delay & -0.44 & $\mathrm{p}=0.01$ \\
\hline Prop hi delay with 'First' time delay & -0.40 & $\mathrm{p}=0.03$ \\
\hline Prop hi delay with 'First' words & -0.37 & $\mathrm{p}=0.04$ \\
\hline Npost with hi know & 0.35 & $\mathrm{p}=0.06$ \\
\hline Hi know with 'First' knowledge & 0.32 & $\mathrm{p}=0.10$ \\
\hline Prop hi know with 'First' knowledge & -0.29 & $\mathrm{p}=0.12$ \\
\hline Prop hi delay with 'First' social aspects & 0.26 & $\mathrm{p}=0.16$ \\
\hline Prop hi delay with 'First' knowledge & -0.26 & $\mathrm{p}=0.17$ \\
\hline Npost with time delay & -0.25 & $\mathrm{p}<0.01$ \\
\hline
\end{tabular}

\section{DISCUSSION}

With particular reference to the frequencies of the phases of knowledge construction at CybErg 2005 (research question 1), the clear majority of knowledge construction was attributed to phase I and III. This replicates the findings of Schellens and Valcke (2004). Gunawardena et al. (1997) state that phase III knowledge construction constitutes "higher mental functions" (p. 415). Thus, even though a large majority of the discussion reflected lower mental functions (phase I) and knowledge construction of a sharing and comparing nature (stating opinions, defining problems and asking questions), there was also a large degree of higher mental functions (phase III) and knowledge construction in the form of negotiating new meanings and the coconstruction of knowledge. Applebee (1984), Garrison et al. (2000), Newman et al. (1996), and White (1993), who compared face-to-face discussion to online discussion, stated that online discussions are preferable for higher-order learning, but lack the creativity and novelty of face-to-face discussions. This study confirmed their proposal as a large amount of discussion did indeed reflect higher mental functions (phase III) resulting in higher order learning, but did not reach the highest creative levels of knowledge construction embodied in phases IV and V with regularity. The clear paucity of phase IV and phase $\mathrm{V}$ knowledge construction reflected a lack of creativity and novelty as these two phases are concerned with the modification of what has been proposed and applications of newly constructed meanings to different settings.

At the posting level, the possible interrelationships between Time delay, Knowledge construction, Social aspects, and Number of words (research question 2) were investigated. It has been suggested that limiting the time frames and parameters for computer-mediated discussion threads and the replies within these discussion threads would improve interactivity and social presence (Pendergast, 2006; Tu, 2002). This study tends to contradict those suggestions as Knowledge construction, Social aspects and the Number of words were generated independently within postings, and not related to the time delay between the original posting and subsequent responses. Gunawardena and Zittle (1997) and Tu (2002) found that when replies to contributions occurred after very lengthy periods in time, this could affect the discussion by detracting from interaction, social presence, and 
negatively affecting the attitudes of the discussion participants. As has been stated, Time delay did not seem to influence any of the above discussed variables which is contrary to Gunawardena and Zittle (1997) and Tu's (2002) findings, although it must be stressed that they only assessed satisfaction with the communication, not any direct content-related dimension (i.e. knowledge construction). From these correlations one can conclude either that participants did not expect prompt responses to their contributions, or that even if their attitudes had been negatively affected by the slow responses, their intellectual contributions were potentially unaffected.

It was found that when a greater number of words were utilised within the postings, this was typically associated with a higher level of knowledge construction. This finding perhaps extends upon Gunawardena et al.'s (1997) proposition, that not only do participants in interaction with one another co-create higher levels of knowledge construction, but that an individual's thoughts may interact with one another, and build from one another, as they form their contribution, resulting in a higher level of knowledge construction as more thoughts are worked through and recorded. The results of this study indicate that Social aspects of the postings did not detract from, or enhance, the effectiveness of the discussions. Thus, whether Social aspects were commonplace within the discussion threads or the discussions were completely on-the-topic all of the time, there was no affect on Time delay, Knowledge construction, or the Number of words.

At the discussion thread level, potential interrelationships between the Number of postings, the Highest level of knowledge construction, the Proportion of the discussion thread at which the highest level of knowledge construction was achieved, and the Proportion of the discussion thread at which the highest time delay existed between postings were investigated (research question 3). A positive relationship of moderate strength was found between the Number of postings within discussion threads and the Highest level of knowledge construction within discussion threads, even though it was statistically non-significant. There would be a moderate chance of greater peaks of knowledge construction within discussion threads if a greater amount of postings were generated. This result is congruent with the proposals put forward by Gunawardena et al. (1997); Levin et al. (1990); and Salomon (1993) that participants interact with one another to further the level of knowledge construction from lower to higher levels within discussion threads. Therefore, as more contributions are made by participants, so the amount of knowledge constructed (potentially) increases. However, the Number of postings within the discussion threads was not related to the Proportions of the discussion threads at which the highest level of knowledge construction was achieved or where the greatest time delay existed between postings. Therefore, no matter the amount of postings generated in discussion, there was no relationship to where the greatest level of knowledge construction will be generated or where the greatest time delay would exist, only that greater levels of knowledge construction might be achieved somewhere in the discussion thread with greater numbers of postings. No relationship existed between the Highest level of knowledge construction within discussion threads and the Proportion of the discussion threads at which either the highest level of knowledge construction was achieved or where the greatest time delay existed. In addition, no relationship was found between the Proportions of the discussion thread at which the highest time delay existed between postings and the Proportions of the discussion thread at which the highest level of knowledge construction was achieved.

In research question 4 we sought to investigate the potential interrelationships between the posting level variables (Time delay, Knowledge construction, Social aspects, and Number of words) and the discussion thread variables (Number of postings, Highest level of knowledge construction achieved, Proportion of the discussion thread at which the highest level of knowledge construction was achieved, and Proportion of the discussion thread at which the highest time delay existed between postings). The results demonstrate that the greatest time delays within discussion threads were associated with the termination of the discussion. The Proportion of the discussion thread at which the highest time delay existed between postings was not related to the actual Time delay, the level of Knowledge construction, Social aspects, or the Number of words at the posting level. Therefore, the actual content of discussions was unaffected by where the greatest time delay existed within the discussion, but the greatest time delay was associated with the proximal termination of the discussion thread. This may be a factor signalling the "natural" termination of a discussion thread. Alternatively, a long time delay between postings may artificially bring a discussion thread to a premature close.

It was investigated whether higher levels of knowledge construction occurred at later stages during the discussion thread due to knowledge being constructed through interaction of multiple postings, rather than knowledge construction remaining stagnant (Gunawardena et al., 1997; Levin et al., 1990; Pea, 1993; Salomon, 1993). This result was confirmed to a reasonable degree noting that the mean of $69 \%$, median of $71 \%$ and mode of $100 \%$ with regards to the Proportion of the discussion thread where the highest level of constructed knowledge occurred. Thus, in the majority of the discussion threads, the highest levels of knowledge were constructed later rather than earlier in the discussion, confirming that knowledge was built and generated rather than just naturally appearing.

This study also investigated whether greater time delays were associated with the termination of the discussion. Considering that the mean, median and mode of Proportion of a discussion thread where the highest Time delay occurred were $71 \%, 75 \%$ and $100 \%$ respectively, it can be seen that the termination of many discussion threads happened once the greatest time delay between postings had just occurred. This could perhaps also be attributed to the fact that the contributors were losing interest in the discussion or had interacted sufficiently within the discussion to the extent that their statements had been made and their questions answered (i.e. the discussion had drawn to a natural close). Alternately, if contributors had lost interest, or their focus had shifted to another discussion thread because of the lengthy time delays, this would draw the discussion to a premature close.

Particular attributes of the "First" reply postings to opening statements were investigated for their potential impact upon later postings within the discussion threads (research question number 5). Quicker responses to opening statements within discussion threads were also associated with greater numbers 
of further postings. However, one possible explanation for the negative relationship between the Number of posts and the "First" time delay is the level of interest in the topic. Perhaps, the discussions which grabbed the interest of many contributors or were perhaps within the specialist fields of the contributors, may have sparked the contributors to participate more actively within these topics compared with other discussion topics. As a result, contributors should respond quickly to generate more discussion. In addition, if the discussion concerned their field of expertise or interest, they would possibly be in a position to be more knowledgeable, or seek more knowledge of that which is being discussed. Therefore, if interest/expertise may affect content of discussion, perhaps including and stimulating online discussions which are hypothesised to be of a particular interest, or within the field of expertise, of the contributors would increase the overall effectiveness of the online discussions. However, as this study was of a purely correlational nature, and it did not take interest or expertise into account, it cannot be shown whether this was the true cause of the relationship or not. It would therefore be advisable for future research to perhaps investigate the effect of interest and expertise on the content of online discussions.

There are a number of limitations to this research that bear noting. First, there was no direct comparison between face-to-face discussions and online textual discussions. The results may therefore be limited to this particular online conference. However, qualitative feedback from the formal evaluation of previous CybErg conferences indicated that participants perceived the quality of online discussions at CybErg conferences to be superior to discussions at similar face-to-face conferences (Thatcher \& James, 2003). Second, the study was correlational in nature and therefore it was not possible to establish causality or the directionality of many of the relationships. Third, the role of contributors' interest and field of expertise were not investigated which may have impacted upon interaction and effectiveness of the discussions. As such, interest and expertise could not be shown to be the cause of some of the relationships discussed. Finally, it was not possible to assess several aspects of the participants-such as their cognitive styles, writing styles, experience, tactics, abilities, English-language proficiency, and personalities. These aspects may have had some impact on the flow of these online discussions.

\section{PRACTICAL IMPLICATIONS}

This section highlights some of the main practical implications that emerge from this study and provides some pointers to online discussion administrators as to how to encourage greater quantity and quality of online discussion.

- $\quad$ Providing time limits for online discussions will not only minimise the total time of the discussion, but knowledge construction, social aspects, and number of words should remain unaffected.

- $\quad$ Encouraging the utilisation of a greater number of words within postings would possibly be a useful tactic to improve knowledge construction and thus the learning processes and effectiveness of the discussion. This could be done by emphasising the importance to the participants of an online discussion that by ensuring their contributions to the discussion are extensive, broad and fully inclusive of all their ideas, feelings, opinions, and previous knowledge, they can aid the overall effectiveness of the discussion.

- The generation of more contributions within online discussions may lead to higher levels of knowledge construction. Timely reminders or alerts could be used to remind contributors to respond to queries.

- If it is assessed that online discussions should continue rather than end, setting short time parameters and stimulating contributors' interest in the discussion might assist in keeping the discussion flowing.

- In contrast, if it is assessed that particular discussion points are taking longer to be addressed and are not adding to the discussion thread they should rather be brought to a close so that participants can concentrate on active discussion threads where knowledge is still being generated in reasonable period of time.

- As time delays within online discussions extended later in the discussion thread, participation was negatively affected and interaction decreased. Reducing the time period allowed and making this time frame known to participants may keep the discussion going for longer.

- $\quad$ By stimulating quicker initiating responses to opening statements within a discussion thread, there is a moderate chance that; a) a greater number of postings will be generated within the discussion threads which in turn leads to; b) a moderate chance that a higher level of knowledge construction will be achieved within the discussion threads, and a small chance that; c) general time delays at the posting level will be decreased. In this way, reducing the time delay of the first reply posting may increase the overall effectiveness of the discussion.

- $\quad$ Finally, social aspects do not appear to detract from or enhance the effectiveness of the discussion. Software that facilitates social aspects (e.g. the insertion of 'smileys') may not necessarily stimulate higher quality or quantity discussions.

\section{CONCLUSION}

These results parallel other results about the differential efficacy of online conversation in comparison to face-to-face conversation. For example, Whittaker (1996) found that online users find discussions in large group settings with other people whom they rarely knew were more useful and rewarding than discussions in a small group with people that were known well. Despite this result an argument can still be made for time parameter guidelines for online discussions. When time delays between postings are reduced, not only will the total time for a discussion be minimised, but the amount of knowledge constructed, social aspects, and number of words should remain unaffected. Alternatively, Anderson and Christansen (2002) have noted that online conferences often have to last over an extended period of time to account for the fact that online participants are often involved in other activities at a second, physically-present location. Garrison et al. (2000) have argued that the longer time delay for text-based discussion is more beneficial since it allows more time for critical reflection and to formulate a coherent, written argument. Likewise, these results demon- 
strate that allowing lengthy online discussions to take place over an extended period of time will not have an adverse effect on the amount of content and knowledge construction within those discussions.

This research has added to the field of knowledge regarding the content of online discussions and their effectiveness. Particular emphasis was placed on the relationships between time delay and content of online discussions which has not been substantially researched. The Gunawardena et al. (1997) IAM was found to be a useful tool for the knowledge construction aspect of the content analysis, and social aspects in discussion were found to neither advantage nor disadvantage the overall effectiveness of the discussion.

\section{REFERENCES}

Applebee, A. N. (1984) Writing and reasoning. Review of Educational Research, 54, 577-596.

Anderson, T. \& Christiansen, J. (2002). Online conferences for professional development. In C. Vrasidas \& G. Glass (Eds.), Online professional development for teachers. Information Age Publishing: Greenwich, CT.

Badri, A., Grasso, F. \& Leng, P. (2003). Evaluation of discussions in online classrooms, in V. Palade, R.J. Howlett, L.C. Jain, (Eds.) Knowledge-Based Intelligent Information and Engineering Systems 7th International Conference, KES 2003, vol. 2774 of Lecture Notes in Artificial Intelligence, Springer-Verlag, p. 193-200.

Cairncross, F. (1997). The Death of Distance: How the Communication Revolution Will Change Our Lives. Boston, MA: Business School Press

Chen, F., Lee, Y., Chu, H., Wang, H., Jiang, H. (2005). Effective discussions, social talks and learning: a paradox on learning in discussion forums. Paper presented at the 2005 conference on Computer support for collaborative learning: learning 2005: the next 10 years!, Taipei, Taiwan.

Conner, P. W. (1992). Networking in the humanities: lessons from ANSAXNET. Computers and the Humanities, 26, 195-204.

Daft, R. L. \& Lengel, R. H. (1986). Organisation information systems, media richness, and structural design. Management Science, 32(4), 554-571.

Garrison, D. R., Anderson, T. \& Archer, W. (2000). Critical Inquiry in a Text-Based Environment: Computer Conferencing in Higher Education. The Internet and Higher Education, 2(2-3), 87-105.

Gay, G., Martin, W. \& Pena-Shaff, J. (2001). An Epistemological Framework for Analysing Student Interactions in Computer-Mediated Communication Environments. Journal of Interactive Learning Research, 12, 41-69.

Glance, N., Siegler, M, Hurst, M., Stockton, R., Nigam, K. \& Tomokiyo, T. (2005). Deriving Marketing Intelligence from Online Discussion. Paper presented at the eleventh ACM SIGKDD international conference on Knowledge discovery in data mining, Chicago, Illinois, USA.

Gunawardena, C. N., Lowe, C. A. \& Anderson, T. (1997). Analysis of a Global Online Debate and the Development of an Interaction Analysis Model for examining Social Construction of Knowledge in Computer Conferencing. Journal of Educational Computing Research, 17(4), 397-431.

Gunawardena, C. N. \& Zittle, F. J. (1997). Social presence as a predictor of satisfaction within a computer-mediated conferencing encironment. The American Journal of Distance Education, 11(3), 8-26.

Harasim, L. M. \& Winkelmans, T. (1990) Computer-mediated collaboration. A case study of an online educational workshop. Knowledge: Creation, Diffusion, Utilization, 4, 382-409.

Hiltz, S. R. (1984). Online Communities. A Case Study of the Office of the Future. Norwood, New Jersey: Publishing Corporation.

Huck, S. W. (2004). Reading Statistics and Research $\left(4^{\text {th }} E d\right.$.). USA: Pearson Education Inc.

Kreijns, K., Kirschner, P. A., \& Jochems, W. (2002). The sociability of computer-supported collaborative learning environments. Educational Technology \& Society, 5(1), 8-22.

Levin, J., Kim, H. \& Riel, M. (1990). Analysing Instructional Interactions on Electronic Message Networks. In Harasim, L. (Ed.), Online Education (pp. 185-213). New York: Praeger.
Lewenstein, B. V. (1995) Do public electronic bulletin boards help create scientific knowledge? The cold fusion case. Science, Technology \& Human Values, 2, 123-149.

Lipponen, L., Rahikainen, M., Lallimo, J., \& Hakkarainen, K. (2001). Analysing patterns of participation and discourse in elementary students' online science discussion. Paper presented at the First European Conference on CSCL, Maastricht, the Netherlands.

Marra, R. M., Moore, J. L. \& Klimczak, A. K. (2004). Content Analysis of Online Discussion Forums: A Comparative Analysis of Protocols. Educational Technology, Research and Development, 52(2), 23-40.

Matzat, U. (2004). Academic communication and Internet Discussion Groups: transfer of information or creation of social contacts? Social Networks, 26, 221-255.

McCarty, W. (1992). Humanist: lessons from a global electronic seminar. Computers and the Humanities, 26, 205-222.

Newman, D. R., Webb, B., \& Cochrane, C. (1996). A content analysis method to measure critical thinking in face-to-face and computer supported group learning. Retrieved May 4, 2007 from http://www.qub.ac.uk/mgt/papers/methods/contpap.html

Newman, D. R., Johnson, C., Webb, B. \& Cochrane, C. (1997). Evaluating the quality of learning in computer supported co-operative learning. Journal of the American Society for Information Science, 48(6), 484-495.

Pea, R. D. (1993). Practices of distributed intelligence and designs for education. In Salomon, G. (Ed.), Distributed Cognitions (pp. 47-87). Cambridge: Cambridge University Press.

Pendergast, M. (2006, June). An Analysis Tool for the Assessment of Student Participation and Implementation Dynamics in Online Discussion Forums. ACM SIGITE Newsletter, 3(2), 10-17.

Rourke, L., Anderson, T., Garrison, D. R. \& Archer, W. (2001). Assessing social presence in asynchronous text-based computer conferencing. Journal of Distance Education, 14(2), 50-71.

Salomon, G. (1993). No distribution without individuals' cognition: A dynamic interactional view. In Salomon, G. (Ed.), Distributed Cognitions (pp. 111-138). Cambridge: Cambridge University Press.

Schoberth, T., Preece, J. \& Heinzl, A. (2003). Online communities: a longitudinal analysis of communication activities. In the proceedings of the 36th Annual Hawaii International Conference on Systems Sciences, Hawaii, January 6-9, 2003.

Schellens, T. \& Valcke, M. (2004). Collaborative learning in asynchronous discussion groups: What about the impact on cognitive processing? Computers in Human Behavior, 21, 957-975.

Sproull, L. \& Kiessler, S. (1986). Reducing social context cues. Electronic mail in organizational communication. Management Science, 32, 1492-1512.

Steinkuchler, C. A., Derry, S. J., Levin, J. R., \& Kim, J. B. (2000). Argumentative reasoning in online discussion. Paper presented at the Annual Meeting of the American Educational Research Association, New Orleans, Los Angeles, USA.

Thatcher, A. (2006, July). Evaluation of online academic conferencing: a longitudinal analysis. Paper presented at the $16^{\text {th }}$ World Congress on Ergonomics (IEA 2006), Maastricht, Netherlands.

Thatcher, A. \& James, J. (2003). Evaluation of virtual conferencing for ergonomics. In the proceedings of the International Ergonomics Association 25th Triennial Congress, Seoul, South Korea, August 25-29, 2003

Thatcher, A., James, J. \& Todd, A. (2005). Proceedings of CybErg 2005. [CD-Rom] The Fourth International Cyberspace Conference on Ergonomics. Johannesburg: International Ergonomics Association Press. ISBN 0957748523.

Tu, C. (2002). The Impacts of Text-based CMC on Online Social Presence Journal of Interactive Online Learning, 1(2), 1-24.

Walther, J. B. (1992). Interpersonal effects of computer-mediated communication: experimental observations over time. Communication Research 19(1), 52-90

Walther, J. B. (1996). Computer-Mediated Communication: Impersonal, Interpersonal and Hyperpersonal Interaction. Communication Research, 23(1), 1-43.

White, E. M. (1993). Assessing higher-order thinking and communication skills in college graduates through writing. The Journal of General Education, 42, 105-122.

Whittaker, S. (1996). Talking to strangers: an evaluation of the factors affecting electronic collaboration. Proceedings of the Computer Supported Cooperative Work Conference, pp. 409-418, Boston, USA, November 16-20, 1996. 


\section{APPENDIX A}

\section{Modified from the Gunawardena et al. (1997) Interaction Analysis Model p. 414}

\section{Phase 1: Sharing and comparing of information.}

- A statement reflecting an observation or opinion

- A statement reflecting agreement with one or more participants

- Supportive examples provided by one or more participants

- Asking and/or answering questions to provide clarification of statements

- Identifying, defining or describing a problem

Phase 2: Discovering and delving into dissonances and inconsistencies amongst ideas, concepts and statements (extending into the realm of cognitive dissonance).

- Statement of disagreement with another participant

- Asking and/or answering questions to provide clarification on reason for disagreement

- Reaffirming the view of the participant, perhaps using experience, literature, collected data or utilising relevant metaphors and analogies to strengthen the participant's point of view

Phase 3: Negotiated meanings and the co-creation of new knowledge

- Clarifying and negotiating meanings of terms

- Negotiating the importance and extent to which specific types of arguments should be furthered

- Identifying areas of agreement or similarity amongst differing concepts

- Utilising compromise and co-construction of knowledge to negotiate and propose new statements

- Accommodation or integration of metaphors and analogies

Phase 4: Testing and modifying co-constructed knowledge and proposed synthesis

- Testing newly created knowledge against the participant's understanding of 'fact' according to their culture.

- Testing against existing mental models

- Testing against the participant's experience

- Testing against collected data

- Testing against contradictions found in literature and/or grounded in theory

Phase 5: Applications of newly constructed meaning and agreement statements

- Providing a summary of agreements amongst participants

- Applying newly constructed knowledge

- Statements by participants illustrating that their ways of thinking and knowledge have been changed or affected as a result of their interaction within the discussion 